\title{
ALIMENTOS EM ZONAS DE CONFLITO: PERSPECTIVAS INTERDISCIPLINARES.
}

\section{Ewerton Reubens Coelho-Costa}

Universidade Estadual do Ceará - UECE - Fortaleza - Ceará - Brasil

\section{RESUMO}

A obra Food in Zones of Conflict: CrossDisciplinary Perspectives, editada em língua inglesa por Paul Collinson e Helen Macbeth, ainda sem tradução para o português, aborda o tema pouco explorado de alimentos, ou a falta deles, em áreas de conflito, na atualidade ou em contextos passados, onde 0 confronto entre combatentes geralmente armados faz surgir consequências materiais de conflito que afetam e moldam indivíduos e a capacidade de grupos sociais para acessar, distribuir e produzir alimentos que pode, inclusive, alterar valores, simbologias e significados sociais por conta das circunstâncias.

A obra salienta o caráter multidimensional dos alimentos a partir de perspectivas diversas, incluindo as da antropologia, estudos de desenvolvimento, nutrição, ciência política, sociologia e relações internacionais. Dentre os temas centrais, destaca-se: a produção, distribuição e disponibilidade de alimentos em zonas de conflito; maior competição por alimentos, terras e recursos que controlam a produção de comida; alimentos sendo utilizados como arma de protagonistas em conflitos; e, a logística nofornecimento de alimentos aos militares atuantes em zonas de conflito.

O livro é composto por dezesseis capítulos, mencionados a seguir: Introdução (p.7) - por Paul Collinson e Helen Macbeth; 1 Try to imagine, we didn't even have salt to cook with!: Food and War in Sierra Leone - por Susan Shepler (p.27); 2 Landmines, cluster bombs and food insecurity in
África - por Bukola Adeyemi Oyeniyi e Akinyinka Akinyoade (p.39); 3 Special nutritional needs in refugee camps: a cross-disciplinary approach - por Jeya Henry e Helen Macbeth (p.53); 4 Patterns of household food consumption in conflict affected households in Trincomalee, Sri Lanka - por Rebecca Kent (p.65); 5 Engaging religion in the Quest for sustainable food security in zones of conflict in subsaharan África - por Lucy Kimaro (p.77); 6 Livestock production in zones of conflict in the Northern border of Mexico - por Doria Deraga (p.85); 7 The logic of war and wartime meals - por Nives Rittig Beljak e Bruno Beljak (p.95); 8 Nutrition, food rationing and home production in the UK during the second world war - por Helen Lightowler e Helen Macbeth (107); 9 Beyond the ration: alternatives to the ration for british soldiers on the Westerm front, 1914-1918 - por Rachel Duffett (p123); 10 Sustaining and conforting the troops in the pacific war - por Katarzyna J. Cwiertka (p133); 11 Enemy cuisine: claiming agency, seeking humanity and renegotiating identity through consumption - por Felícia Campbell (p.145); 12 The memory of food problems at the end of the first world war in subsequent propaganda posters in Germany por Tania Rusca (p.155); 13 Echoes of catastrophe: famine, conflict and reconciliation in the Irish borderlands - Paul Collinson (p. 171); 14 Land to the Tiller: hunger and the end of monarchy in Ethiopia Benjamin Talton (p.185); 15 Prospects for conflict to spread through bilateral land arrangements for food security - por Michael. J. Strauss (p.197); e, 16 Food, conflict and human rights: accounting for structural violence - por Ellen Messer (p.209). 
Um dos temas mais decorrentes ao longo do texto é a exploração de como o alimento torna-se altamente politizado e usado como arma política e militar, com vários capítulos que examinam esse mote, de forma convincente demonstrando como governos e outros grupos poderosos exploram disponibilidade e acesso aos alimentos. Esses capítulos elucidam a complexa interação entre a segurança alimentar, conflitos armados e poder político, mostrando as circunstâncias de guerras em "elevar as múltiplas dimensões e significados de comida e bebida em extremas dimensões" (p. 134).

Os autores exploram ainda as consequências de intervenções para enfrentar problemas de segurança alimentar e nutrição, e atentam para as maneiras de como estes problemas devem ser pesquisados e gerenciados (Beljak e Beljak, p.95). Além disso, três capítulos (Cwiertka [p.133], Duffett [123], e Campbell [p.145]) tecem considerações sobre o papel que os governos desempenham na provisão de alimentos, tanto para os cidadãos quanto para militares, em zonas de conflito.

Os alimentos podem se tornar armas de barganha e negociações, que podem unir ou desunir pessoas e contribuir para a dissolução de fronteiras sociais - ao mesmo tempo em que pode estabelecer e realçar fronteiras, como mostram os capítulos de Cwiertka (p.133), Campbell (p.145) e Collinson (p.171). Os capítulos de Strauss (p.197) e Messer (p.209) fornecem narrativas individuais de sofrimento humano, onde os alimentos em zonas de conflito são explorados como política que traz as intimidades e individualidades da fome tendo a politização e militarização como pano de fundo - aqui se apresentam a capacidade humana de criar e inovar em práticas alimentares no mais terrível dos contextos.

As narrativas de guerra em Serra Leoa, apresentadas por Shepler (p.27), trata da violência e do sofrimento humano ilustrando o alimento a partir de experiências e memórias de conflito, improvisação criativa e adaptação dos novos caminhos da comida como base para a conciliação no pós-guerra. Ainda são apresentadas as engenhosidades de transformação de alimentos, para torná-los palatáveis em períodos de escassez, como o caso de conflitos croatas apresentados por Beljak e Beljak (p.95), observando novas simbologias e materiais incorporados para a saciedade.

Campbell (p.145) escreve a partir de uma perspectiva privilegiada, o que torna este capítulo auto-etnográfico e, talvez, o mais marcante e instigante de todo 0 livro. Baseando-se em experiências de ter estado no exército dos EUA durante a Guerra do Golfo, a autora explica como era a realidade de refeições do tipo MREs (Meals Ready to Eat), ou seja, comidas prontas para comer a partir de reidratação, ela e seus colegas permaneceram com fome e, consequentemente, foram conduzidos ao longo das linhas inimigas por seu desejo de comida iraquiana. Campbell fala do "comer a comida inimiga", fazendo o "desconhecido, perigoso e repugnante, longe do seguro e do familiar" por conta da necessidade de um consumo "rebelde" (p.148), no qual ela e outros soldados expressaram a sua própria agência; um processo que, por sua vez, abre a possibilidade de humanizar ou desumanizar o inimigo. Ela localiza assim a humanidade no mais desumano dos ambientes.

Os temas centrais estão bem identificados na introdução e no decorrer da obra estão bem estruturados, mas utilizar mais recursos, como imagens e comentários de mais pessoas que vivenciaram tais conflitos, deixaria o texto mais atrativo e engrandeceria, ainda mais, a construção teórica - além de prender mais a atenção dos leitores. São dezesseis capítulos, geralmente, curtos que poderiam ter uma análise mais aprofundada teoricamente.

Trata-se de uma contribuição valiosa para um tema muitas vezes esquecido e pouco explorado, que também oferece estudos de caso inovadores e originais e dados empíricos importantes sobre temas como segurança alimentar e da pobreza, nutrição e intervenção política. É excelente leitura para ser utilizada no ensino e pesquisa de graduação e pósgraduação. 


\section{Referências}

COLLINSON, Paul; MACBETH, Helen (Ed.). Food in Zones of Conflict: Cross-disciplinary Perspectives. New York and Oxford: Berghahn Books, 2014. ISBN 978-1-78238-403-8 (Paper) ISBN 978-1-78238-404-5 (Ebook) 